\title{
The type-species of Psilochlorops Duda (Diptera, Chloropidae) and its position in the phylogeny of the genus, with the description of a new species
}

\author{
Paula Riccardi ${ }^{1,2} \&$ Dalton Amorim ${ }^{1}$
}

\author{
${ }^{1}$ Department of Biology, Faculdade de Filosofia, Ciências e Letras de Ribeirão Preto, Universidade de São Paulo, Av. dos Bandeirantes, 3900 , \\ 14040-901 Ribeirão Preto-SP, Brazil. \\ ${ }^{2}$ Corresponding author: paula_riccardi@yahoo.com.br
}

\begin{abstract}
The type-species of Psilochlorops Duda (Diptera, Chloropidae) and its position in the phylogeny of the genus, with the description of a new species. The genus Psilochlorops is known only for the Neotropical Region and had six described species to date. Psilochlorops niger sp. nov. is herein described and the male genitalia of $P$. clavitibia, the type-species of the genus, is described in detail. A new cladistic analysis of Psilochlorops is presented, including all known species of the genus.
\end{abstract}

KEYWORDS. Chloropinae; Insecta; Neotropics; taxonomy.

The genus Psilochlorops Duda belongs to the subfamily Chloropinae. In the phylogeny proposed for the subfamily by Paganelli (2002), including only the Neotropical representatives, its sister-group is Bricelochlorops Paganelli. Both genera have a strict Neotropical occurrence and are the only representatives of the Psilochlorops-group sensu Paganelli. Psilochlorops includes six species described from South America (Riccardi \& Amorim 2012). In a previous cladistic study of the genus (Riccardi \& Amorim 2012), the type-species, Psilochlorops clavitibia Duda, was available, but could not be included in the final tree due to lack of information about the male genitalia. More recently, a new species of Psilochlorops was discovered, P. niger sp. nov. from Peru and Bolivia, herein described; as well material of P. clavitibia was made available. The male terminalia of $P$. clavitibia are described and illustrated, and a new cladistic analysis is made including all seven known species of the genus. Despite the statement in the original description of P. clavitibia that the holotype is a male, actually it is a female. Here we record for the first time a male of this species.

\section{MATERIAL AND METHODS}

The material presented in this study was kindly loaned by the curator of the Smithsonian National Museum of Natural History (USNM). Most characters were described in Riccardi \& Amorim (2012), as well as the remaining species of the genus. The morphological nomenclature follows Cumming \& Wood (2009), except for the mesolobus (fused male cerci) (Andersson 1977).

Six new characters and $P$. niger sp. nov. were added and the missing data for P. clavitibia in the matrix of Riccardi \& Amorim (2012) were included (Table I). The cladistic analysis was carried out in the software NONA (Goloboff 1993) using the interface provided by the software Winclada (Nixon
2004). Multistate characters were treated as unordered in the analyses and parameters "rs 0 , hold 10000 , hold/300, mult*300".

Thaumatomyia sp., Parectecephala humeralis (Duda, 1930), Ectecephala albistylum Macquart, 1851, Diplotoxa versicolor (Loew, 1863), Bricelochlorops peregrinus Paganelli, 2002, and Bricelochlorops celutae Carvalho-Filho \& Esposito, 2010 were used as outgroups. In Nartshuk's (2012) system, Psilochlorops, Bricelochlorops and Parectecephala belong to the tribe Chloropini, Diplotoxa belongs to the Diplotoxini, Thaumatomyia belongs to the Mindini, while Ectecephala is unplaced. Of these species, only B. peregrinus was not examined directly; the data on the species were taken from the original description (Paganelli 2002: p. 40-41, 89-90).

\section{TAXONOMY}

\section{Psilochlorops niger sp. nov. (Figs. 1-5)}

Diagnosis. Ocellar triangle dark brown, shiny, margins straight, almost reaching anterior margin of frons; frons anteriorly with yellow fine transversal margin; scutum blackish; apex of mesolobus bilobed in posterior view.

Description (male). Total length, $4.8-6.8 \mathrm{~mm}$. Wing length $3.2-4.8 \mathrm{~mm}$.

Head (Figs. 1, 3). Blackish, as wide as thorax, longer than broad in dorsal view, longer than deep in lateral view; ocellar triangle dark brown, shiny, margins straight, almost reaching anterior margin of frons; anterior edge of frons yellow, like a fine transversal stripe; occiput dark, slightly convex, with fine setulae; gena about 0.34 height of eye; postgena about 0.74 height of eye; parafacialia narrow, yellowish; eye rounded, long axis horizontal; face yellow, with a dark central stripe; clypeus black, dusted; labellum yellow, proboscis regular; palpus yel- 


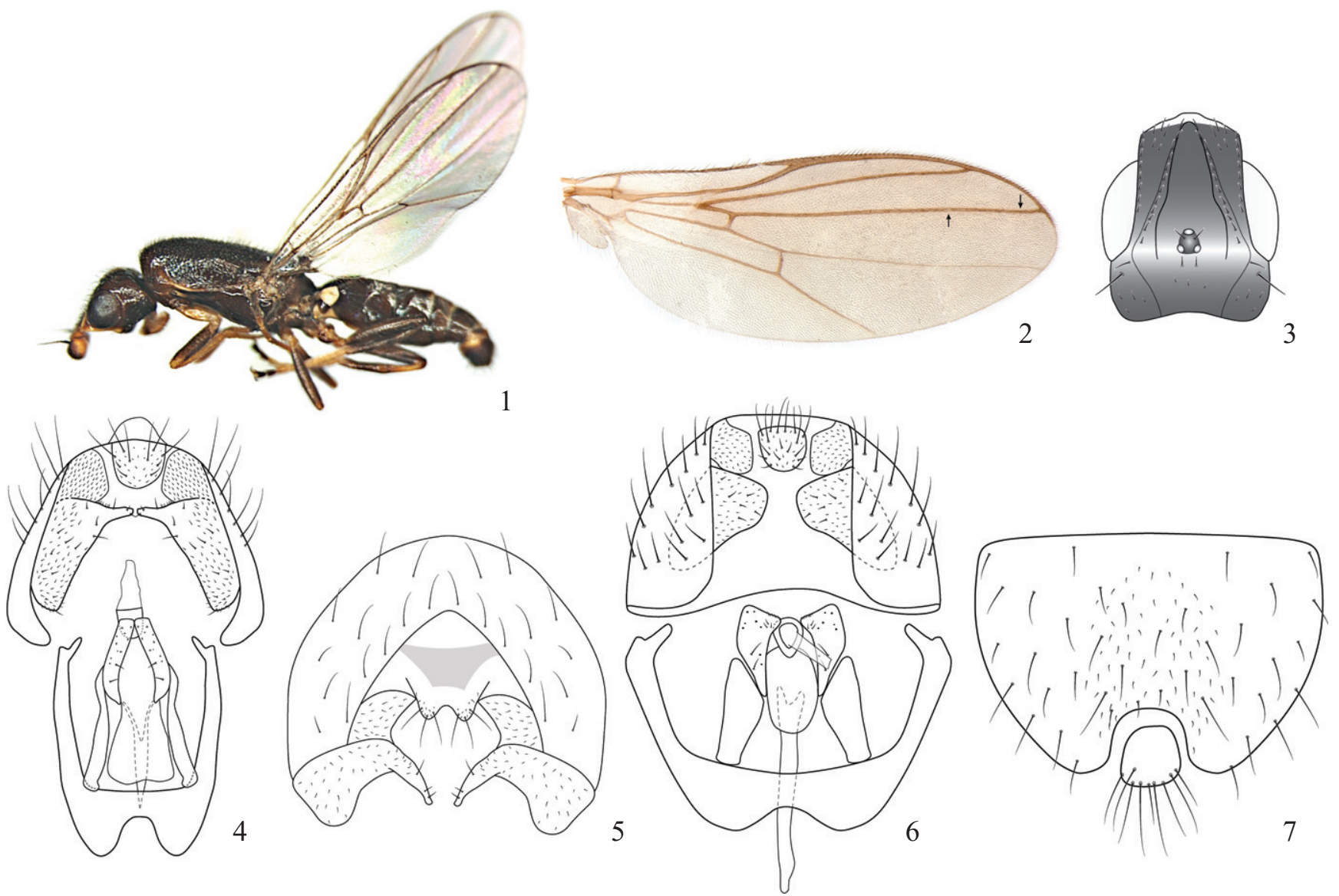

Figs. 1-7. 1-5, Psilochlorops niger sp. nov. (holotype). 1, habitus. 2, wing (arrows point to a sinuosity in $\mathrm{R}_{4+5}$ ). 3, head (dorsal view). 4, male genitalia (ventral view). 5, epandrium (posterior view). 6-7, P. clavitibia. 6, male genitalia (ventral view). 7, epandrium (posterior view).

Table I. Character matrix and taxa used in the cladistic analysis.

\begin{tabular}{llllllllllllllllllll}
\hline & 0 & 1 & 2 & 3 & 4 & 5 & 6 & 7 & 8 & 9 & 0 & 1 & 2 & 3 & 4 & 5 & 6 & 7 & 8 \\
\hline Thaumatomyia sp. & 0 & 1 & 0 & 0 & 0 & 0 & 0 & 0 & 0 & 0 & 0 & 1 & 1 & 0 & 4 & 0 & 0 & 0 & 0 \\
Parectecephala humeralis & 0 & 1 & 0 & 0 & 0 & 0 & 0 & 0 & 0 & 0 & 1 & 0 & 0 & 0 & 0 & 0 & 0 & 1 & 0 \\
Ectecephala albistylum & 1 & 1 & 0 & 0 & 0 & 0 & 0 & 0 & 0 & 0 & 1 & 0 & 0 & 0 & 0 & 0 & 1 & 1 & 0 \\
Diplotoxa versicolor & 0 & 0 & 0 & 0 & 0 & 0 & 1 & 0 & 0 & 0 & 0 & 0 & 0 & 2 & 4 & 0 & 1 & 0 & 1 \\
Bricelochlorops peregrinus & 1 & 0 & 1 & 1 & 1 & 0 & 0 & 1 & 1 & 0 & 1 & 1 & 1 & $?$ & 1 & 1 & 1 & 1 & 1 \\
Bricelochlorops celutae & 0 & 0 & 1 & 1 & 1 & 1 & 1 & 1 & 1 & 0 & 1 & 1 & 1 & 1 & 1 & 0 & 1 & 1 & 1 \\
Psilochlorops nigrifemur & 1 & 0 & 0 & 2 & 2 & 1 & 1 & 0 & 0 & 1 & 1 & 0 & 1 & 1 & 1 & 0 & 1 & 0 & 1 \\
Psilochlorops brunneus & 0 & 1 & 0 & 2 & 2 & 1 & 1 & 0 & 0 & 1 & 2 & 0 & 1 & 1 & 2 & 1 & 1 & 0 & 1 \\
Psilochlorops clavitibia & 1 & 1 & 0 & 2 & 2 & 1 & 1 & 0 & 0 & 1 & 2 & 0 & 1 & 1 & 2 & 1 & 1 & 0 & 0 \\
Psilochlorops niger sp. nov. & 0 & 0 & 0 & 2 & 2 & 1 & 1 & 0 & 0 & 1 & 2 & 0 & 1 & 1 & 1 & 1 & 1 & 0 & 1 \\
Psilochlorops elongatus & 0 & 0 & 0 & 2 & 2 & 1 & 1 & 0 & 0 & 1 & 2 & 0 & 1 & 1 & 0 & 1 & 0 & 0 & 1 \\
Psilochlorops paganelliae & 0 & 0 & 0 & 1 & 1 & 1 & 0 & 0 & 0 & 1 & 2 & 0 & 1 & 1 & 0 & 1 & 0 & 0 & 1 \\
Psilochlorops flavisoma & 0 & 0 & 0 & 1 & 1 & 1 & 1 & 0 & 0 & 1 & 2 & 0 & 1 & 2 & 3 & 1 & 0 & 0 & 1 \\
\hline
\end{tabular}

low, darkened apically, cylindrical. Antennae dark yellow; pedicel short, with a dark brown area apically, slightly longer than deep; arista thin, dark brown, with scattered dark pubescence. One row of interfrontal setulae outside of ocellar triangle; 10 reduced fronto-orbital setulae; one pair of ocellars present; postocellars parallel and pointing upright; inner verticals inconspicuous, outer verticals well developed; one row of dark peristomal setulae at lower margin of gena; no vibrissa.
Thorax (Fig. 1). Typical propleural carina present. Scutum less than twice as long as broad, blackish, stripes indistinct, fine dark brown sparse setosity. Scutellum dark brown, triangular, wider than long. Pleuron shiny dark brown, yellowish near anterior spiracle, postpronotum with an inconspicuous mark, without bristles. Present are the following macrochaetae: one pair of anterior and posterior postalar; one pair of dorsocentral; prescutellar setae indistinct; anterior notopleural indistinct; two posterior notopleural. Base of halter dark brown, knob pale yellow. Fore and mid legs yellow, femora brownish. Hind legs dark brown, femur slightly swollen; proximal half of tarsus yellow and distal half of tarsus dark brown; tibial organ narrow, less than half length of tibia, yellowish. Wing (Fig. 2). Hyaline; costal sections: 6: 5: 2.5: 1.9. $\mathrm{R}_{2+3}, \mathrm{R}_{4+5}$, and $\mathrm{M}_{1+2}$ nearly straight; $\mathrm{R}_{4+5}$ and $\mathrm{M}_{1+2}$ slightly divergent; $\mathrm{r}-\mathrm{m}$ and $\mathrm{dm}$-cu parallel, distance from each other equals $2.6 \mathrm{dm}-\mathrm{cu}$ lengths. $\mathrm{CuA} 1$ with a week flexure.

Abdomen. Long, slender, shiny, with long, thin setae; tergites dark brown. Male genitalia (Figs. 4-5). Hypandrium longer than broad, with a pair of ventral projections. Surstylus setose except for its apex, with some tiny bristles, not fused with epandrium; mesolobus (the fused cerci) almost square in ventral view, with apex bilobed in posterior view.

Female. unknown. 
Etymology. From Latin "niger", meaning black. The gender is masculine.

Comments. Both type specimens were measured. The hind tibiae are slightly enlarged midway toward the apex compared with the tibiae of $P$. clavitibia. The rugosity of the gena is almost indistinct.

Type material. Holotype: M, Peru, Cuzco, Paucartambo, Puente San Pedro (ca. 50 km NW Pilcopata; 1303.3'S, 71³2.8'W) 1600 m, 3.ix.1988, Wayne N. Mathis col. (USNM). Paratype: M, Bolivia, La Paz: Yolosa, organ, 1185m, 18.iii.2001, Wayne N. Mathis col. (USNM).

\section{Psilochlorops clavitibia Duda, 1931}

Psilochlorops clavitibia Duda, 1931: 168. Type-locality: Bolivia, Mapirí, Lorenzopata. Distr. - Bolivia. Sabrosky \& Paganelli, 1984: 39 (cat.).

Male genitalia (Figs. 6-7). Hypandrium broader than long, with a pair of ventral projections and short arms; phallapodeme long. Surstylus setose, fused to epandrium, similar in shape to P. brunneus.

Material examined. One specimen, M, Bolivia, La Paz, Puente Villa (2 km E); $16^{\circ} 24^{\prime} \mathrm{S} 67^{\circ} 38^{\prime} \mathrm{W} ; 1960 \mathrm{~m}, 11$. iii.2001, Wayne N. Mathis col. (USNM).

\section{Key to the species of Psilochlorops (modified from Riccardi \& Amorim 2012)}

1. Frons brown; scutum brownish, with or without blackish stripes; hind tibia dark

\section{2}

- Frons yellow; scutum yellowish, with distinct brown stripes, hind tibia variable

\section{5}

2. Ocellar triangle with margins at most gently curved; interfrontals inside or outside ocellar triangle; color of legs variable

- Ocellar triangle with margins clearly sigmoid; one row of interfrontals inside ocellar triangle; legs yellow, except for dark femora, hind tibia almost entirely dark . Psilochlorops nigrifemur Riccardi \& Amorim

3. Ground color of scutum pale yellow, frons brown with apex rounded and slightly projected forwards; ocellar triangle brown with margins far from eyes; occiput bare.... Psilochlorops brunneus Riccardi \& Amorim

- Ground color of scutum dark yellow or dark brown; frons dark yellow or dark brown, straight, slightly or not projecting; ocellar triangle dark brownish with margins almost reaching eyes; occiput with fine setulae....

4. Ground color of scutum dark yellow, with distinct longitudinal stripes; frons entirely dark yellow; interfrontals inside ocellar triangle; face entirely dark

\section{Psilochlorops clavitibia Duda}

- Scutum dark brown, with indistict longitudinal stripes; frons dark brown, yellow anteriorly (Fig. 3); interfrontals outside ocellar triangle; face yellow, with a dark spot.

Psilochlorops niger sp. nov.
5. Head rather longer than broad in dorsal view; postpronotum with a brown spot and three bristles; long axis of eye almost vertical; scutum twice as long as broad, lateral stripe almost separated into an anterior and a posterior separate maculae Psilochlorops elongatus Riccardi \& Amorim

- Head broader than long in dorsal view; postpronotum with one or two bristles; long axis of eye diagonal; scutum less than twice as long as broad, a single, elongated lateral stripe at each side 6

6. Ocellar triangle reaching anterior margin of frons; gena and postgena of the same height, about one third of eye height .... Psilochlorops paganelliae Riccardi \& Amorim - Ocellar triangle not reaching anterior margin of frons; gena about one fifth of eye height, postgena about half of height Psilochlorops flavisoma Riccardi \& Amorim

Phylogenetic relationships. The monophyly of Psilochlorops was already confirmed by Riccardi \& Amorim (2012), with a phylogenetic study for the genus. Nineteen morphological characters are used in the present analysis, with six new characters added here (indicated by an asterisk). All 13 characters previously used by Riccardi \& Amorim (2012) were included, but with minor modifications: a new state was added to characters 4 and 5, and one state was removed from character 16.

1. Interfrontal bristles: (0) out of ocellar triangle; (1) on ocellar triangle.

2. Ocellar triangle*: (0) without longitudinal furrow; (1) with longitudinal furrow.

3. Longitudinal black stripe on ocellar triangle*: (0) absent; (1) present.

4. Gena extension: (0) narrow; (1) regular; (2) broad.

5. Postgena extension: (0) narrow; (1) regular; (2) broad.

6. Gena rugosity: (0) absent; (1) present

7. Arista color: (0) yellow; (1) brown/black.

8. Clypeus: (0) regular; (1) swollen.

9. Pedicel shape: (0) regular; (1) enlarged.

10. Scutum surface: (0) convex (1) flattened

11. Scutum dimensions*: (0) as long as broad; (1) up to 1.5 times longer than broad; (2) more than 1.5 times longer than broad.

12. Posterior edge of scutellum*: (0) triangular; (1) rounded.

13. Tibial organ: (0) absent; (1) present.

14. $\mathrm{R}_{4+5}{ }^{*}$ : (0) straight; (1) slightly sinuose distally (Fig. 2); (2) convex distally.

15. Mesolobus format: (0) rectangular; (1) bilobed; (2) almost square; (3) indistinct; (4) oval.

16. Surstylus fusion into epandrium: (0) absent; (1) present.

17. Surstylus microtrichia: (0) absent; (1) present.

18. Arrangement of gonites *: (0) aligned; (1) parallel.

19. Phallapodeme: (0) long; (1) short.

The results from this new analysis are entirely congruent with the relationships found by Riccardi \& Amorim (2012). The polytomy including $P$. brunneus, $P$. nigrifemur and a clade with $P$. paganelliae, . elongatus and P. flavisoma were resolved, although the new species described in this paper resulted in a new polytomy being added to the topology. Psilochlorops clavitibia comes out as the sister species of $P$. brunneus. The analysis resulted in a single most parsimonious tree (Fig. 8), with 45 steps, consistency index 0.57 , and retention index 0.71 . 


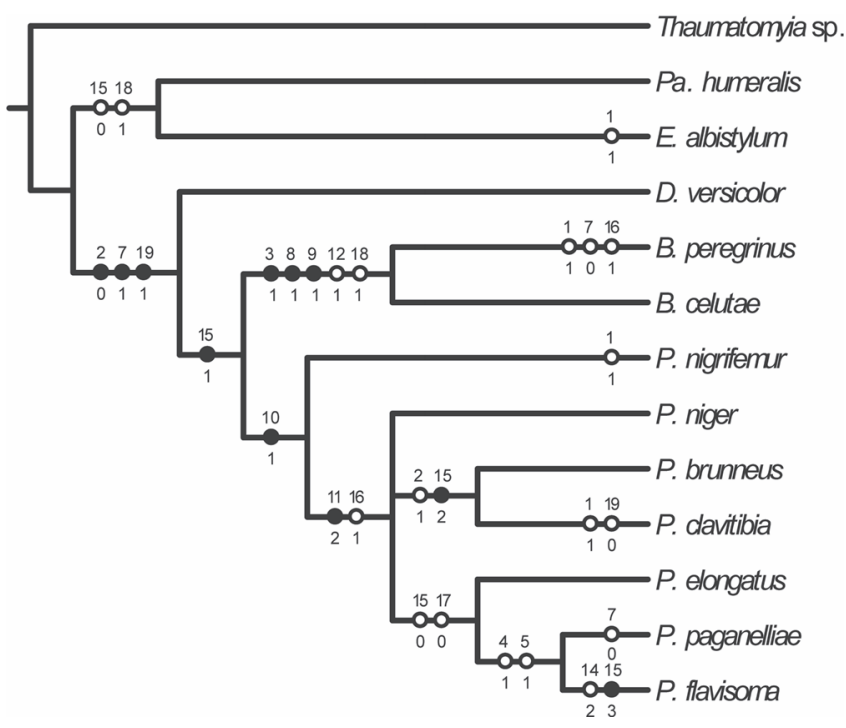

Fig. 8. Single most parsimonious tree of the species of Psilochlorops, obtained with the outgroups Thaumatomyia sp., Parectecephala humeralis "Pa. humeralis", Ectecephala albistylum, Diplotoxa versicolor, Bricelochlorops peregrinus, and Bricelochlorops celutae. Length of 45 steps, consistency index 0.57 , and retention index 0.71 .

\section{DISCUSSION}

Characters 7 (1, dark arista) and 19 (1, phallapodeme short) are shared by the Psilochlorops-group, but the derived state is also found in other genera of Chloropinae including Diplotoxa. This quite means that the intergeneric relationships found in the cladogram are useful to properly root the analysis of the Psilochlorops-group, but do not reliably depict the relationships among chloropine genera.

In addition to the characters shared by the Psilochloropsgroup, character 14 (1) (Fig. 2) seems to be synapomorphic for this clade with reversion to state 2 in P. flavisoma. This character still remains uncertain because the wing of $B$. peregrinus could not be properly examined.

It is possible to notice a bilobed mesolobus $(15,1)$ in the most basal species, $P$. nigrifemur, a character shared with Bricelochlorops. This feature is retained in P. niger less strongly, being modified to an almost square outline in $P$. brunneus $+P$. clavitibia, and rectangular in P. elongatus $+P$. paganelliae (with $P$. flavisoma being indistinct).
Gena and postgena extended $(4,2 ; 5,2)$, scutum flat dorsally $(10,1)$, and gonites aligned $(18,0)$ are the characters which define Psilochlorops in this analysis. Despite this, gena broad and gonites aligned are present in many other genera of Chloropinae.

Scutum prolonged $(11,2)$ and surstylus fusion $(16,1)$ establish the clade $P$. niger $+($ P. brunneus + P. clavitibia $)+($ P. elongatus $+($ P. paganelliae + P. flavisoma $))$. Again, these features are not unique in Chloropinae, but together and allied to the less inclusive characters, they seem to be enough to support this clade.

Psilochlorops elongatus $+($ P. paganelliae + P. flavisoma $)$ share the loss of microtrichia in the surstyli $(17,0)$. This clade was recovered in a previous analysis (Riccardi \& Amorim 2012). However, the inclusion of $P$. clavitibia and $P$. niger in the present analysis is remarkably an advance for the knowledge of Psilochlorops because P. nigrifemur could be defined as most basal in the genus and the evolution of some genitalic structures could be traced.

\section{AKNOWLEDGMENTS}

We thank Dr Allen Norrbom and Lucrecia Rodriguez (USNM) for the loan of the studied material. The preparation of this paper benefitted from a FAPESP $\mathrm{PhD}$ fellowship Grant \# 2012/12843-0 to the first author.

\section{REFERENCES}

Andersson, H. 1977. Taxonomic and phylogenetic studies on Chloropidae (Diptera) with special reference to Old World genera. Entomologica Scandinavica 8: $1-200$

Cumming, J.M. \& Wood, D.M. 2009. Adult morphology and terminology, p. 9-50. In: Brown, B.V., Borkent, A., Cumming, J.M., Wood, D.M., Woodley, N.E. \& Zumbado, M.A. (Eds.), Manual of Central American Diptera, Vol. 1. Ottawa, NRC Research Press, xi+714 p.

Goloboff, P.A. 1993. NONA. Version 1.6 (for Windows). [Computer software and manual]. INSUE Fundación y Instituto Miguel Lillo.

Nartshuk, E.P. 2012. A check list of the world genera of the family Chloropidae (Diptera, Cyclorrhapha, Muscomorpha). Zootaxa 3267: 1-43.

Nixon, K.C. 2004. Winclada. Version 1.89. [Computer software and manual]. Ithaca, New York, USA.

Paganelli, C.H.M. 2002. Insecta-Diptera-Chloropidae: revisão dos gêneros neotropicais de Chloropinae (Incl. Mindidae). Fauna da Amazônia Brasileira 24: 1-101.

Riccardi, P.R. \& Amorim, D.S. 2012. Revision and cladistic analysis of Neotropical genus Psilochlorops Duda (Diptera: Chloropidae). Zootaxa 3326: $37-48$. 